\title{
Comparison of efficiency of ozone and chlorhexidine subgingival irrigation in orthodontic patients for controlling gingival inflammation
}

SADJ March 2019, Vol. 74 No. 2 p82 - p86

VKV Sandra ${ }^{1}$, RR Nagireddy ${ }^{2}$, A Nooney ${ }^{3}$, M Nadhamuni ${ }^{4}$

\section{ABSTRACT}

\section{Aim}

To compare the clinical effects of subgingival irrigation with ozonated water to the effects of chlorhexidine solution on gingivitis in orthodontic patients and to correlate the clinical effects with the MCP-1 activity in gingival crevicular fluid (GCF).

\section{Objective}

Correlate the inflammatory marker monocyte chemoattractant protein (MCP-1) in GCF with clinical parameters viz. gingival index $(\mathrm{Gl})$, plaque index $(\mathrm{Pl})$, gingival bleeding index (GBI), probing pocket depth (PPD).

\section{Materials and method}

A double-blind clinical study of subgingival irrigation was conducted in a split-mouth design on 30 subjects for 28 days. Clinical parameters (plaque index, gingival index, gingival bleeding index, probing pocket depth) and MCP-1 enzyme activity were measured at baseline followed by subgingival irrigation with $0.01 \mathrm{mg} / \mathrm{l}$ of ozonated water on right maxillary quadrants and $0.02 \%$ of chlorhexidine solution on left maxillary quadrants. These parameters were again assessed on $14^{\text {th }}$ and $28^{\text {th }}$ day.

\section{Results}

Significant $(P<0.01)$ reduction of all the clinical parameters and GCF MCP-1 activity after subgingival irrigation with both solutions. Ozonated water showed a highly significant reduction of clinical parameters and MCP-1 activity.

\section{Author affiliations:}

1. Venkata Kala Vani Sandra: M.D.S (PGIMER, Chandigarh, India), Head of the Department of Orthodontics, C.K.S Theja Institute of Dental Sciences \& Research, Tirupati, Andhra Pradesh, India.

2. Ravindra Reddy Nagireddy: M.D.S (Bapuji Dental College \& Hospital, Davanagere, India), Head of the Department of Periodontics, C.K.S Theja Institute of Dental Sciences \& Research, Tirupati, Andhra Pradesh, India.

3. Anitha Nooney: M.D.S (Orthodontics), Private practitioner, Rwanda.

4. Madhuri Nadhamuni: Post graduate student, Department of Orthodontics, C.K.S Theja Institute of Dental Sciences \& Research, Tirupati, Andhra Pradesh, India

Corresponding author: Kala Vani Sandra

HOD, Department of Orthodontics and Dentofacial Orthopaedics,

CKS Theja Institute of Dental Sciences \& Research, Tirupati, Andhra

Pradesh, India. Tel: +9194 40423242 Email: drsvkvani@gmail.com

\section{ACRONYMS \\ Elisa: $\quad$ Enzyme-Linked Immunosorbent Assay \\ GBI: Gingival Bleeding Index \\ GCF: $\quad$ Gingival Crevicular Fluid \\ MCP-1: Monocyte Chemoattractant Protein \\ PI: $\quad$ Plaque Index \\ PPD: $\quad$ Probing Pocket Depth}

\section{Conclusion}

Subgingival ozone irrigation can be an effective method to reduce gingival inflammation in orthodontic patients.

Keywords

Gingival inflammation, Ozonated water, Chlorhexidine solution, MCP-1.

\section{INTRODUCTION}

Fixed orthodontic appliance treatment tends to promote dental plaque accumulation and gingival inflammation, related to the difficulties posed in maintaining optimal oral hygiene. In time, plaque accumulation around orthodontic appliances may lead to gingivitis, enamel decalcification and white spot lesion formation. ${ }^{1-4}$

In order to overcome these problems, numerous preventive strategies are used and recommended in the literature..$^{5-7}$ These strategies are mainly focused on the elimination of the cariogenic microflora or the mechanical removal of the plaque. ${ }^{8}$

Ozone therapy is amongst these strategies and nowadays the ozone treatment is gaining wider acceptance in dentistry. In the field of orthodontics, ozone gas has been tested for its anticariogenic effect, for its effect on the shear bond strength of orthodontic brackets to enamel and on the presence of gingival inflammation. ${ }^{9-11}$

The aim of the study was to compare the clinical effects of subgingival irrigation with ozonated water to those seen with chlorhexidine solution irrigation on gingivitis in patients with fixed orthodontic appliances and also to correlate the clinical effects with the MCP-1 activity in the GCF. 


\section{MATERIALS AND METHODS}

\section{Study sample}

A total of 30 subjects aged between 21-23 were enrolled in the study. The participants had no relevant medical history and had not taken antibiotics nor used antibacterial mouth rinse within the last month. The inclusion criterion was having been under fixed orthodontic appliance treatment for a minimum of three months.

The participants were informed about the study well in advance and informed consent was obtained. Ethical clearance was granted by the Ethical Committee of the C.K.S. Theja Institute of Dental Sciences \& Research, Tirupati.

\section{Method}

This study was conducted for 28 days. The study period was divided into three-time intervals i.e. baseline (day 0), day 14 , day 28. A split-mouth design was used in this study of subgingival irrigation. The right and left maxillary quadrants were irrigated with ozonated water and chlorhexidine solution respectively and were designated as the experimental and control sides respectively.

\section{Clinical procedure}

At the baseline, clinical parameters such as plaque index, ${ }^{12}$ gingival index ${ }^{13}$ and gingival bleeding index ${ }^{14}$ were recorded at distofacial, facial, mesiofacial and the entire lingual gingival marginal surfaces of all the teeth present. The probing pocket depth was also determined, using William's periodontal probe for the same surfaces. The value was registered to the nearest millimetre boundary/division. All the recordings of clinical parameters were made by the same calibrated examiner, who was blinded as to the treatment condition. GCF samples were collected from both sides of each maxillary quadrant followed by subgingival irrigation.

\section{Ozone irrigation}

The right half of the upper quadrant was irrigated with $0.01 \mathrm{mg} / \mathrm{l}$ ozonated water that was released from a dental jet (Kent Ozone Dental jet TY- 820, Pure Water House, Bangalore, India). The device released a single pulsating stream of ozonated water from the nozzle. The speed and pressure of the flow could be varied from 350 to $500 \mathrm{kPa}$ with an ozone output of $0.082 \mathrm{mg} / \mathrm{h}$, at a noise output of $<70 \mathrm{~dB}$ and a water outflow of $\geq 450 \mathrm{ml}$. A 22-gauge blunt needle was bent and attached to the tip of the nozzle of the device. The crevice was irrigated with ozonated water by inserting the needle $3 \mathrm{~mm}$ subgingivally. A stop clock was used to set the irrigation time to $15 \mathrm{sec}$ at each site. A total time of $5-10$ min was spent for the irrigation for each patient.

\section{Chlorhexidine irrigation}

The other half of the quadrant were irrigated with $0.2 \%$ chlorhexidine solution released from a "Water Pik". A 22-gauge blunt needle was bent and attached to the tip of the nozzle of the device. Irrigation was done at the low-pressure setting.

\section{GCF sampling procedure}

GCF was collected using $1-3 \mu$ l calibrated volumetric microcapillary pipettes obtained from Sigma Aldrich Chemical Company, USA (Catalog No.p0549). By placing the tip of the pipette extracrevicularly (unstimulated) for 5-20 minutes and referring to the calibration on the micropipette, a standardized volume of $2 \mu \mathrm{l}$ GCF was collected using from each test site. After collection, the samples were stored in a refrigerator at $-20^{\circ} \mathrm{C}$ in the Department. of Anthropology, Tirupati for subsequent biochemical analysis.

\section{Patient's instructions}

After irrigation, the patients were directed to follow oral hygiene habits regularly, using a standard Ortho toothbrush and paste provided to each. The patients were instructed to report on the $14^{\text {th }}$ and $28^{\text {th }}$ day following irrigation treatment.

\section{Quantification of inflammatory mediators - MCP-1 by enzyme-linked immunosorbent assay}

The assay was based on Sandwich Elisa. Capture antibody was coated on an Elisa plate and stabilized by coating stabilizer. Standards and samples containing antigen were added to the wells and incubated. During incubation, antigen and antibody complexes were formed. This complex was detected by using biotinlabelled tracer antibody conjugated with streptavidinhorse radish peroxidase.

Addition of a tetramethylbenzidine (TMB) substrate produced colour which could be monitored at a wavelength of $450 \mathrm{~nm}$ by the ELISA reader. A calibrated standard curve, plotted with optical density values of the standards, was used to approximate the concentrations of MCP-1 in the tested samples.

\section{Statistical analysis}

Statistical data was subjected to: an Independent t-test to compare the data between test and control samples at various durations, a Pearson correlation test to correlate between clinical and biochemical parameters, and an ANOVA test to analyze the differences among group means. For all the tests, $\mathrm{P} \leq 0.05$ was considered statistically significant.

\section{RESULTS}

The results of the study are reported in Tables 1-13. The interpretation of clinical and microbial data was done on the information gathered at baseline and on the $14^{\text {th }}$ and $28^{\text {th }}$ days. A significant reduction was observed for all the clinical parameters with both ozone and chlorhexidine irrigation (Tables 1-3).

A higher percentage of reduction of PI (71.4\%), Gl (74.6\%) and $\mathrm{GBI}(93 \%)$ was observed with ozone irrigation as compared with chlorhexidine. No such drastic reduction in PPD was observed when a comparison was made between the data of the experimental and control sides taken on the $14^{\text {th }}$ and $28^{\text {th }}$ days (Table 4 ). 
Besides affecting the clinical parameters, ozonated water irrigation also caused significant reduction in the GCF MCP-1 enzyme activity from baseline to $14^{\text {th }}$ day, from $14^{\text {th }}$ to $28^{\text {th }}$ day and also from baseline to $28^{\text {th }}$ day. The percentile reduction of MCP-1 (57.9\%) using ozone was appreciable as compared with chlorhexidine $(45.7 \%)$ from baseline to the $28^{\text {th }}$ day. (Table 5)

Results also showed a statistically significant positive correlation between the concurrent changes of clinical parameters and MCP-1 values on both sides.

\begin{tabular}{|c|c|c|c|c|c|c|c|}
\hline Day & Side & $\begin{array}{l}\text { No. of } \\
\text { Samples }\end{array}$ & Mean & S.D & $\begin{array}{c}\% \\
\text { Reduction }\end{array}$ & $\begin{array}{c}\mathbf{t}^{\mathrm{V}} \\
\text { Value }\end{array}$ & $\begin{array}{c}p \\
\text { Value }\end{array}$ \\
\hline \multirow{2}{*}{ Day 0} & Experimental & 30 & 2.243 & 0.143 & - & \multirow{2}{*}{1.026} & \multirow{2}{*}{$0.078^{\star \star}$} \\
\hline & Control & 30 & 2.127 & 0.293 & - & & \\
\hline \multirow{2}{*}{ Day 14} & Experimental & 30 & 1.190 & 0.214 & 46.8 & \multirow{2}{*}{-10.709} & \multirow{2}{*}{$0.000^{*}$} \\
\hline & Control & 30 & 1.670 & 0.212 & 21.2 & & \\
\hline \multirow{2}{*}{ Day 28} & Experimental & 30 & 0.647 & 0.161 & 71.4 & \multirow{2}{*}{-7.977} & \multirow{2}{*}{$0.000^{\circ}$} \\
\hline & Control & 30 & 0.997 & 0.199 & 53.3 & & \\
\hline
\end{tabular}

\begin{tabular}{|c|c|c|c|c|c|c|c|}
\hline Day & Side & $\begin{array}{l}\text { No. of } \\
\text { Samples }\end{array}$ & Mean & S.D & $\begin{array}{c}\% \\
\text { Reduction }\end{array}$ & $\begin{array}{c}\mathbf{t} \\
\text { Value }\end{array}$ & $\begin{array}{c}p \\
\text { Value }\end{array}$ \\
\hline \multirow{2}{*}{ Day 0} & Experimental & 30 & 2.130 & 0.149 & - & \multirow{2}{*}{1.110} & \multirow{2}{*}{$0.137^{\star \star}$} \\
\hline & Control & 30 & 2.040 & 0.271 & - & & \\
\hline \multirow{2}{*}{ Day 14} & Experimental & 30 & 1.200 & 0.087 & 43.6 & \multirow{2}{*}{13.083} & \multirow{2}{*}{$0.000^{*}$} \\
\hline & Control & 30 & 1.660 & 0.175 & 18.6 & & \\
\hline \multirow{2}{*}{ Day 28} & Experimental & 30 & 0.540 & 0.210 & 74.6 & \multirow{2}{*}{8.449} & \multirow{2}{*}{$0.002^{*}$} \\
\hline & Control & 30 & 1.030 & 0.241 & 49.5 & & \\
\hline
\end{tabular}

\begin{tabular}{|c|c|c|c|c|c|c|c|}
\hline Day & Side & $\begin{array}{l}\text { No. of } \\
\text { Samples }\end{array}$ & Mean & S.D & $\begin{array}{c}\% \\
\text { Reduction }\end{array}$ & $\stackrel{t}{t}$ & $\begin{array}{c}p \\
\text { Value }\end{array}$ \\
\hline \multirow{2}{*}{ Day 0} & Experimental & 30 & 13.030 & 7.699 & - & \multirow{2}{*}{-0.340} & \multirow{2}{*}{$0.471^{* \star}$} \\
\hline & Control & 30 & 12.870 & 6.703 & - & & \\
\hline \multirow{2}{*}{ Day 14} & Experimental & 30 & 4.500 & 2.874 & 65.4 & \multirow{2}{*}{-7.895} & \multirow{2}{*}{$0.000^{*}$} \\
\hline & Control & 30 & 10.130 & 3.857 & 21.2 & & \\
\hline \multirow{2}{*}{ Day 28} & Experimental & 30 & 0.870 & 1.634 & 93.0 & \multirow{2}{*}{-7.319} & \multirow{2}{*}{$0.000^{*}$} \\
\hline & Control & 30 & 5.470 & 3.711 & 57.4 & & \\
\hline
\end{tabular}

\section{DISCUSSION}

This double-blind prospective clinical study was carried out to evaluate and compare the clinical effects on gingivitis of a single subgingival irrigation with $0.01 \mathrm{mg} / 1$ ozonated water with effects associated with $0.2 \%$ chlorhexidine irrigation in patients with fixed orthodontic appliances and also to correlate the clinical parameters with the MCP-1 activity in GCF.

The results showed significant reduction for all the clinical parameters from baseline to $14^{\text {th }}$ day, from $14^{\text {th }}$ to $28^{\text {th }}$ day and also from baseline to $28^{\text {th }}$ day on both the ozonated water irrigated side $(p<0.01)$ and the chlorhexidine irrigation side $(p<0.01)$. The results followed an expected pattern as seen in the study conducted by Dhingra and Vandana. ${ }^{11}$ Schlagenhauf et al. ${ }^{15}$ showed that ozonated water was highly effective in killing both Gram + ve and -ve oral microorganisms in vitro.
However, the statistical comparisons showed that the ozonated water- irrigated side experienced a highly significant reduction of mean PI, GI, GBI scores, whilst the mean PPD score showed no significant change. A higher \% reduction of $\mathrm{PI}, \mathrm{Gl}, \mathrm{GBI}$ was also reported by Kshitish and Laxman, ${ }^{16}$ who compared the effects of ozone to chlorhexidine in patients with chronic and aggressive periodontitis. Furthermore, they reported that the percentile reduction of Actinobacillus actinomycetemcomitans (Aa) (25\%) using ozonated water was appreciable as compared with no change in Aa occurrence using chlorhexidine solution.

The possible mechanism for the reduction in the $\mathrm{PI}$ and gingival inflammation associated with subgingival ozone irrigation may be the antibacterial effect on the plaque microorganisms or may be by disruption of subgingival plaque rather than an instant killing of microorganisms. Huth et al. ${ }^{17,18}$ showed that NF-Kb activity in oral cells in periodontal ligament tissue from the root surfaces of periodontally damaged teeth was inhibited following incubation with aqueous ozone $(20 \mu \mathrm{g} / \mathrm{ml})$, suggesting that it has an anti-inflammatory capability.

Although there was a significant reduction in $\mathrm{GBI} \%$ scores in this study at both $14^{\text {th }}$ and $28^{\text {th }}$ days indicating that reduction was maintained throughout the study duration of 28 days, it cannot be assumed that GBI scores would have been maintained had the duration of the study been longer. A prolonged observation period will allow a better estimation of the effect of the extinction.

The significant reduction in probing depth seen at $14^{\text {th }}$ day $(33.4 \%)$ and $28^{\text {th }}$ day (44\%) on both sides could have resulted from a reduction in gingival inflammation.

The MCP-1 marker in GCF was selected because its activity may increase around teeth wearing orthodontic appliances even if they do not undergo orthodontic movement, possibly as a consequence of gingival inflammation produced by the presence of plaque retentive appliances. ${ }^{19}$

\begin{tabular}{|c|c|c|c|c|c|c|c|}
\hline Day & Side & $\begin{array}{l}\text { No. of } \\
\text { Samples }\end{array}$ & Mean & S.D & $\begin{array}{c}\% \\
\text { Reduction }\end{array}$ & $\begin{array}{c}t \\
\text { Value }\end{array}$ & $\begin{array}{c}p \\
\text { Value }\end{array}$ \\
\hline \multirow{2}{*}{ Day 0} & Experimental & 30 & 2.600 & 0.621 & - & \multirow{2}{*}{0.000} & \multirow{2}{*}{$1.000^{* *}$} \\
\hline & Control & 30 & 2.600 & 0.621 & - & & \\
\hline \multirow{2}{*}{ Day 14} & Experimental & 30 & 1.730 & 0.538 & 33.4 & \multirow{2}{*}{0.000} & \multirow{2}{*}{$1.000^{* *}$} \\
\hline & Control & 30 & 1.730 & 0.538 & 33.4 & & \\
\hline \multirow{2}{*}{ Day 28} & Experimental & 30 & 1.430 & 0.626 & 45 & \multirow{2}{*}{0.000} & \multirow{2}{*}{$1.000^{* *}$} \\
\hline & Control & 30 & 1.430 & 0.626 & 45 & & \\
\hline
\end{tabular}

\begin{tabular}{|c|c|c|c|c|c|c|c|}
\hline Day & Side & $\begin{array}{l}\text { No. of } \\
\text { Samples }\end{array}$ & Mean & S.D & $\begin{array}{c}\% \\
\text { Reduction }\end{array}$ & $\begin{array}{c}t \\
\text { Value }\end{array}$ & $\begin{array}{c}p \\
\text { Value }\end{array}$ \\
\hline \multirow{2}{*}{ Day 0} & Experimental & 30 & 416.643 & 28.376 & - & \multirow{2}{*}{-0.553} & \multirow{2}{*}{$0.584^{\star \star}$} \\
\hline & Control & 30 & 419.307 & 28.779 & - & & \\
\hline \multirow{2}{*}{ Day 14} & Experimental & 30 & 291.643 & 21.197 & 30 & \multirow{2}{*}{-21.765} & \multirow{2}{*}{$0.000^{*}$} \\
\hline & Control & 30 & 366.723 & 7.679 & 12.6 & & \\
\hline \multirow{2}{*}{ Day 28} & Experimental & 30 & 151.077 & 14.105 & 63.7 & \multirow{2}{*}{-17.641} & \multirow{2}{*}{$0.000^{*}$} \\
\hline & Control & 30 & 227.363 & 17.723 & 45.7 & & \\
\hline
\end{tabular}


There was indeed a significant reduction in in MCP-1 enzyme activity from baseline to the $14^{\text {th }}$ day, from $14^{\text {th }}$ to $28^{\text {th }}$ day and also from baseline to $28^{\text {th }}$ day in both the ozone and chlorhexidine irrigation sites. The baseline GCF MCP-1 levels on experimental and control sides were $38.93 \mathrm{pg} / \mu \mathrm{l}$ and $39.71 \mathrm{pg} / \mu \mathrm{l}$ respectively.

\begin{tabular}{|c|c|c|c|c|c|c|}
\hline & $\mathbf{N}$ & GI & PI & GBI & PPD & LDH \\
\hline \multirow{2}{*}{ GI } & \multirow{2}{*}{30} & \multirow{2}{*}{1.000} & 0.543 & 0.624 & 0.565 & 0.704 \\
\hline & & & 0.002 & 0.003 & 0.003 & 0.000 \\
\hline \multirow{2}{*}{ PI } & \multirow{2}{*}{30} & 0.543 & \multirow{2}{*}{1.000} & 0.489 & 0.376 & 0.633 \\
\hline & & 0.002 & & 0.003 & 0.038 & 0.000 \\
\hline \multirow{2}{*}{ GBI } & \multirow{2}{*}{30} & 0.624 & 0.489 & \multirow{2}{*}{1.000} & 0.511 & 0.429 \\
\hline & & 0.003 & 0.034 & & 0.004 & 0.027 \\
\hline \multirow{2}{*}{ PPD } & \multirow{2}{*}{30} & 0.565 & 0.376 & 0.511 & \multirow{2}{*}{1.000} & 0.378 \\
\hline & & 0.003 & 0.038 & 0.004 & & 0.039 \\
\hline \multirow{2}{*}{ LDH } & \multirow{2}{*}{30} & 0.704 & 0.633 & 0.429 & 0.378 & \multirow{2}{*}{1.000} \\
\hline & & 0.000 & 0.000 & 0.027 & 0.039 & \\
\hline
\end{tabular}

\begin{tabular}{|c|c|c|c|c|c|c|}
\hline & $\mathbf{N}$ & GI & PI & GBI & PPD & LDH \\
\hline \multirow{2}{*}{ GI } & \multirow{2}{*}{30} & \multirow{2}{*}{1.000} & 0.195 & 0.174 & 0.267 & 0.762 \\
\hline & & & 0.302 & 0.359 & 0.154 & 0.000 \\
\hline \multirow{2}{*}{ PI } & \multirow{2}{*}{30} & 0.195 & \multirow{2}{*}{1.000} & 0.042 & 0.061 & 0.116 \\
\hline & & 0.302 & & 0.825 & 0.750 & 0.541 \\
\hline \multirow{2}{*}{ GBI } & \multirow{2}{*}{30} & 0.174 & 0.042 & \multirow{2}{*}{1.000} & 0.247 & 0.276 \\
\hline & & 0.359 & 0.825 & & 0.188 & 0.140 \\
\hline \multirow{2}{*}{ PPD } & \multirow{2}{*}{30} & 0.267 & 0.061 & 0.247 & \multirow{2}{*}{1.000} & 0.215 \\
\hline & & 0.154 & 0.750 & 0.188 & & 0.255 \\
\hline \multirow{2}{*}{ LDH } & \multirow{2}{*}{30} & 0.762 & 0.116 & 0.276 & 0.215 & \multirow{2}{*}{1.000} \\
\hline & & 0.000 & 0.541 & 0.140 & 0.255 & \\
\hline
\end{tabular}

\begin{tabular}{|c|c|c|c|c|c|c|}
\hline & $\mathbf{N}$ & GI & PI & GBI & PPD & LDH \\
\hline \multirow{2}{*}{ GI } & \multirow{2}{*}{30} & \multirow{2}{*}{1.000} & 0.454 & 0.584 & 0.744 & 0.941 \\
\hline & & & 0.041 & 0.051 & 0.042 & 0.000 \\
\hline \multirow{2}{*}{ PI } & \multirow{2}{*}{30} & 0.454 & \multirow{2}{*}{1.000} & 0.620 & 0.867 & 0.695 \\
\hline & & 0.041 & & 0.042 & 0.032 & 0.039 \\
\hline \multirow{2}{*}{ GBI } & \multirow{2}{*}{30} & 0.584 & 0.620 & \multirow{2}{*}{1.000} & 0.897 & 0.782 \\
\hline & & 0.051 & 0.042 & & 0.000 & 0.001 \\
\hline \multirow{2}{*}{ PPD } & \multirow{2}{*}{30} & 0.744 & 0.867 & 0.897 & \multirow{2}{*}{1.000} & 0.818 \\
\hline & & 0.042 & 0.032 & 0.000 & & 0.025 \\
\hline \multirow{2}{*}{ LDH } & \multirow{2}{*}{30} & 0.941 & 0.695 & 0.782 & 0.818 & \multirow{2}{*}{1.000} \\
\hline & & 0.000 & 0.039 & 0.001 & 0.025 & \\
\hline
\end{tabular}

\begin{tabular}{|c|c|c|c|c|c|c|}
\hline & $\mathbf{N}$ & GI & PI & GBI & PPD & LDH \\
\hline \multirow{2}{*}{ GI } & \multirow{2}{*}{30} & \multirow{2}{*}{1.000} & 0.301 & 0.246 & 0.402 & 0.978 \\
\hline & & & 0.150 & 0.159 & 0.028 & 0.000 \\
\hline \multirow{2}{*}{ PI } & \multirow{2}{*}{30} & 0.301 & \multirow{2}{*}{1.000} & 0.594 & 0.506 & 0.336 \\
\hline & & 0.105 & & 0.001 & 0.004 & 0.069 \\
\hline \multirow{2}{*}{ GBI } & \multirow{2}{*}{30} & 0.246 & 0.594 & \multirow{2}{*}{1.000} & 0.666 & 0.316 \\
\hline & & 0.159 & 0.001 & & 0.000 & 0.089 \\
\hline \multirow{2}{*}{ PPD } & \multirow{2}{*}{30} & 0.402 & 0.506 & 0.666 & \multirow{2}{*}{1.000} & 0.420 \\
\hline & & 0.028 & 0.004 & 0.000 & & 0.021 \\
\hline \multirow{2}{*}{ LDH } & \multirow{2}{*}{30} & 0.978 & 0.336 & 0.316 & 0.420 & \multirow{2}{*}{1.000} \\
\hline & & 0.000 & 0.069 & 0.089 & 0.021 & \\
\hline
\end{tabular}

\begin{tabular}{|c|c|c|c|c|c|c|}
\hline & $\mathbf{N}$ & GI & PI & GBI & PPD & LDH \\
\hline \multirow{2}{*}{ GI } & \multirow{2}{*}{30} & \multirow{2}{*}{1.000} & 0.573 & 0.546 & 0.502 & 0.980 \\
\hline & & & 0.001 & 0.002 & 0.004 & 0.000 \\
\hline \multirow{2}{*}{ PI } & \multirow{2}{*}{30} & 0.573 & \multirow{2}{*}{1.000} & 0.364 & 0.362 & 0.539 \\
\hline & & 0.001 & & 0.048 & 0.049 & 0.002 \\
\hline \multirow{2}{*}{ GBI } & \multirow{2}{*}{30} & 0.546 & 0.364 & \multirow{2}{*}{1.000} & 0.553 & 0.890 \\
\hline & & 0.002 & 0.048 & & 0.002 & 0.001 \\
\hline \multirow{2}{*}{ PPD } & \multirow{2}{*}{30} & 0.502 & 0.362 & 0.553 & \multirow{2}{*}{1.000} & 0.499 \\
\hline & & 0.004 & 0.049 & 0.002 & & 0.005 \\
\hline \multirow{2}{*}{ LDH } & \multirow{2}{*}{30} & 0.980 & 0.539 & 0.890 & 0.499 & \multirow{2}{*}{1.000} \\
\hline & & 0.000 & 0.002 & 0.01 & 0.005 & \\
\hline
\end{tabular}

\begin{tabular}{|c|c|c|c|c|c|c|}
\hline & $\mathbf{N}$ & GI & PI & GBI & PPD & LDH \\
\hline \multirow{2}{*}{ GI } & \multirow{2}{*}{30} & \multirow{2}{*}{1.000} & 0.369 & 0.789 & 0.477 & 0.948 \\
\hline & & & 0.045 & 0.051 & 0.003 & 0.000 \\
\hline \multirow{2}{*}{ PI } & \multirow{2}{*}{30} & 0.369 & \multirow{2}{*}{1.000} & 0.741 & 0.583 & 0.863 \\
\hline & & 0.045 & & 0.063 & 0.001 & 0.001 \\
\hline \multirow{2}{*}{ GBI } & \multirow{2}{*}{30} & 0.789 & 0.741 & \multirow{2}{*}{1.000} & 0.607 & 0.634 \\
\hline & & 0.051 & 0.063 & & 0.000 & 0.004 \\
\hline \multirow{2}{*}{ PPD } & \multirow{2}{*}{30} & 0.477 & 0.583 & 0.607 & \multirow{2}{*}{1.000} & 0.489 \\
\hline & & 0.003 & 0.001 & 0.000 & & 0.006 \\
\hline \multirow{2}{*}{ LDH } & \multirow{2}{*}{30} & 0.948 & 0.863 & 0.634 & 0.489 & \multirow{2}{*}{1.000} \\
\hline & & 0.000 & 0.001 & 0.004 & 0.006 & \\
\hline
\end{tabular}

\begin{tabular}{|c|c|c|c|c|}
\hline & & Mean value & F value & $P$ value \\
\hline \multirow{2}{*}{ GI } & Between sides & 19.164 & \multirow{2}{*}{778.283} & \multirow{2}{*}{$0.000^{*}$} \\
\hline & Within sides & 0.025 & & \\
\hline \multirow{2}{*}{ PI } & Between sides & 19.770 & \multirow{2}{*}{642.918} & \multirow{2}{*}{$0.000^{\star}$} \\
\hline & Within sides & 0.031 & & \\
\hline \multirow{2}{*}{ GBI } & Between sides & 1170.233 & \multirow{2}{*}{50.007} & \multirow{2}{*}{$0.000^{*}$} \\
\hline & Within sides & 23.402 & & \\
\hline \multirow{2}{*}{ PPD } & Between sides & 11.011 & \multirow{2}{*}{29.536} & \multirow{2}{*}{$0.000^{*}$} \\
\hline & Within sides & 0.373 & & \\
\hline \multirow{2}{*}{ LDH } & Between sides & 529548.211 & \multirow{2}{*}{1093.013} & \multirow{2}{*}{$0.000^{\star}$} \\
\hline & Within sides & 484.485 & & \\
\hline
\end{tabular}

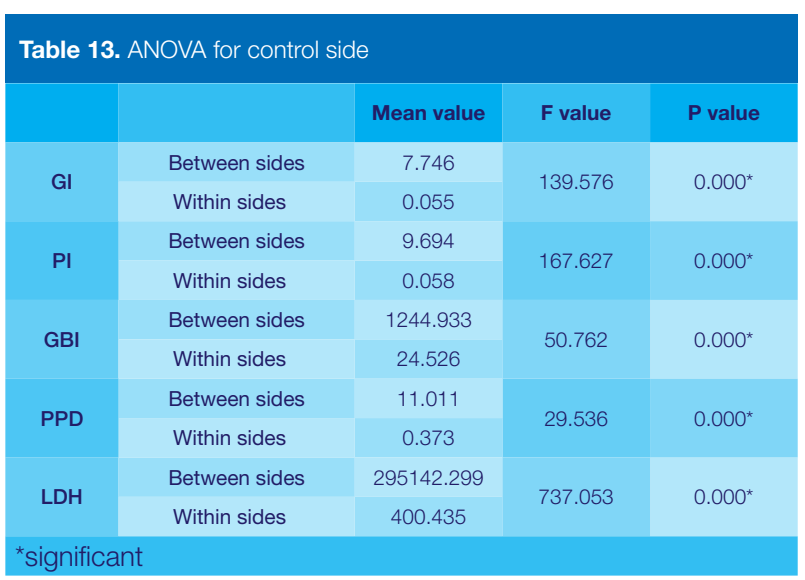

These results were in concord with $\mathrm{Yu}$ et al. ${ }^{20}$ who found that MCP-1 is expressed in inflamed gingival tissue as it plays an important role in the recruitment of monocytes and the amplification of inflammatory signals in bacterially induced inflammation. The GCF MCP-1 levels 
in our study reduced significantly from $38.93 \mathrm{pg} / \mu \mathrm{l}$ to $16.36 \mathrm{pg} / \mu \mathrm{l}$ at $28^{\text {th }}$ day after ozone irrigation $(\mathrm{p}<0.01)$ and from $39.71 \mathrm{pg} / \mu \mathrm{l}$ to $21.53 \mathrm{pg} / \mu \mathrm{l}$ on control side $(p<0.01)$.

When the effects of the irrigants were compared, the data of the ozonated water showed a highly significant reduction in MCP-1 concentration $(p<0.01)$. Concurrently, changes in GCF MCP-1 values and the clinical parameters and PPD between baseline and $28^{\text {th }}$ day, evaluated using Spearman's correlation coefficient, were also seen to exhibit a significant correlation on both experimental and control sides.

At the end of one month, reduction of gingival inflammation in orthodontic patients was appreciable with a single subgingival irrigation of $0.01 \mathrm{mg} / \mathrm{l}$ ozonated water as compared with $0.2 \%$ chlorhexidine. Thus, subgingival ozone irrigation can be an effective method that can be performed during monthly visits on orthodontic patients to reduce the gingival inflammation.

Considering the limitation of this study in terms of short duration, ozone can be considered as a promising anti-inflammatory agent in periodontal therapy. Further long-term studies are required to adequately assess the efficacy of ozone with respect to the frequency and duration of application.

\section{Conflicts of interest}

None

\section{References}

1. Gorelick L, Geiger AM, Gwinnett AJ. The incidence of white spot formation after bonding and banding. Am J Orthod. 1982; 81:93-8.

2. O'Reilly MM, Featherstone JD. Demineralization and remineralization around orthodontic appliances: an in vivo study. $\mathrm{Am} \mathrm{J}$ Orthod Dentofacial Orthop. 1987; 92:33-40.

3. AL Mulla AH, Kharsa SA, Kjellberg H, Birkhed D. Caries risk profiles in orthodontic patients at follow-up using Cariogram. Angle Orthod. 2009; 79:323- 30.

4. Almos NA, AL Mulla AH, Birkhed D. Caries risk profile using the Cariogram in governmental and private orthodontic patients at de-bonding. Angle Orthod. 2012; 82:267-74.

5. Stecksen-Blicks C, Holgerson PL, Olsson M, Bylund B, Sjostrom I, Skold-Larsson K. Effect of xylitol on mutans streptococci and lactic acid formation in saliva and plaque from adolescents and young adults with fixed orthodontic appliances. Eur J Oral Sci. 2004; 112:244-8.

6. Brochner A, Christensen C, Kristensen B, Tranæus S, Karlsson L, Sonnesen L. Treatment of white spot lesions with casein-phosphopeptide stabilized amorphous calcium phosphate. Clin Oral Invest. 2011; 15: 369-73.

7. Du M, Cheng N, Tai B, Jiang H, Li J, Bian Z. Randomized controlled trial on fluoride varnish application for treatment of white spot lesion after fixed orthodontic treatment. Clin Oral Investig. 2012; 16: 463-8.

8. Zimmer BW, Rottwinkel Y. Assessing patient-specific decalcification risk in fixed orthodontic treatment and its impact on prophylactic procedures. Am J Orthod Dentofacial Orthop. 2004; 126: 318-24.

9. Kronenberg O, Lussib A, Ruf S. Preventive effect of ozone on the development of white spot lesions during multibracket appliance therapy. Angle Orthod. 2009; 79: 64-9.
10. Cehreli SB, Guzey A, Arhun N, Cetinsahin A, Unver B. The effects of prophylactic ozone pre-treatment of enamel on shear bond strength of orthodontic brackets bonded with total or self-etch adhesive systems. Eur J Dent. 2010; 4: 367-73.

11. Dhingra K, Vandana KL. Management of gingival inflammation in orthodontic patients with ozonated water irrigation-a pilot study. Int J Dent Hyg. 2011; 9: 296-302.

12. Silness $\mathrm{P}$, Loe H. Periodontal disease in pregnancy. Acta Odontol Scand 1964; 22: 121-7.

13. Loe H, Silness P. Periodontal disease in pregnancy. Acta Odontol Scand 1963; 21: 533-8.

14. Ainamo J, Bay I. Problems and proposals for recording gingivitis and plaque. Int Dent J. 1975; 25: 229.

15. Schlagenhauf $U$, Horlacher V, Netuschil L, Brecx M. The effect of repeated subgingival oxygen irrigations in previously untreated deep periodontal pockets. J Clin Periodontol. 1994; 21: 48-50.

16. Kshitish D, Laxman VK. The use of ozonated water and $0.2 \%$ chlorhexidine in the treatment of periodontitis patients. Indian $\mathrm{J}$ Dent Res. 2010; 21: 341-8.

17. Huth KC, Jakob FM, Saugel B, Cappello C, Paschos E, Hollweck R. Effect of ozone on oral cells compared with established antimicrobials. Eur J Oral Sci. 2006; 114: 435-40.

18. Huth KC, Saugel B, Jakob FM . Effect of aqueous ozone on the NF-kappa B system. J Dent Res 2007; 86: 451-6.

19. Capelli J, Kantarci A, Haffajee A, Teles RP, Fidel JR, Figueredo M. Matrix metaloproteinases and chemokines in gingival crevicular fluid during orthodontic movement. Eur J Orthod. 2011; 10: 1-7.

20. Yu XZ, Antoniades H, Graves D. Expression of monocyte chemoattractant protein-1 in human inflammed gingival tissues. Infecte Immune.1993; 61: 4622-8. 